\title{
Clinicopathological significance of CHFR methylation in non- small cell lung cancer: a systematic review and meta-analysis
}

\author{
Chen Wang ${ }^{1}$, Wenxia Ma ${ }^{1}$, Rong Wei ${ }^{1}$, Xiaoqin Zhang ${ }^{1}$, Ningning Shen ${ }^{1}$, Lifang \\ Shang ${ }^{1}$, Li ${ }^{1}$, Ying Wang ${ }^{1}$, Lifang Gao ${ }^{1}$, Xin Li $^{1}$, Bin Wang ${ }^{1}$, Yaping Zhang ${ }^{1}$ and \\ Aiping Du ${ }^{1}$ \\ ${ }^{1}$ Department of Pathology, The Second Hospital of Shanxi Medical University, Taiyuan, Shanxi, 030001, P.R. China
}

Correspondence to: Aiping Du, email: aiping_du@yahoo.com

Keywords: CHFR, NSCLC, biomarker, methylation, ADC

Received: July 03, $2017 \quad$ Accepted: September 25, $2017 \quad$ Published: October 23, 2017

Copyright: Wang et al. This is an open-access article distributed under the terms of the Creative Commons Attribution License 3.0 (CC BY $3.0)$, which permits unrestricted use, distribution, and reproduction in any medium, provided the original author and source are credited.

\section{ABSTRACT}

Checkpoint with Forkhead-associated and Ring finger domains (CHFR) is a G2/M checkpoint and tumor-suppressor gene. Recent publications showed the correlation of CHFR promoter methylation with clinicopathological significance of non-small cell lung cancer (NSCLC), however, the results remain inconsistent. The aim of this study is to investigate the Clinicopathological significance of CHFR promoter methylation in NSCLC with a meta-analysis. A total of nine studies were included in the metaanalysis that $\mathbf{8 1 6}$ patients were involved. Our data indicated that the frequency of CHFR promoter methylation was higher in NSCLC than in normal lung tissue, Odd Ratios (OR) was 9.92 with $95 \%$ corresponding confidence interval (CI) 2.17-45.23, $\boldsymbol{p}=0.003$. Further subgroup analysis revealed that $C H F R$ promoter was more frequently methylated in squamous cell carcinoma (SCC) than in adenocarcinoma (ADC), OR was 4.46 with 95\% CI 1.65-12.05, $p=0.003$, suggesting the mechanism of SCC pathogenesis is different from ADC. Notably, CHFR promoter methylation was correlated with smoking behavior in NSCLC. In conclusion, CHFR could be a biomarker for diagnosis of NSCLC, and a promising drug target for development of gene therapy in SCC. CHFR promoter methylation is potentially associated with poor overall survival, additional studies need to be carried out for confirmation in future.

\section{INTRODUCTION}

Lung cancer is one of the most common malignancies and the leading cause of cancer-related mortality in the world. Lung cancer can be classified into two major histological groups, small cell lung cancer and non-small cell lung cancer (NSCLC). NSCLC accounts for more than $80 \%$ of all lung cancers, whereas $15-20 \%$ is small cell lung cancer $[1,2]$. NSCLC can be divided into three subtypes of adenocarcinoma (ADC), squamous cell carcinoma (SCC) and large-cell carcinoma, within them, adenocarcinomas accounts for $40 \%$, squamous cell carcinoma for $25-30 \%$, and large-cell carcinoma for $10-15 \%[3,4]$. Although lung cancer subtypes share some genetic variations such as inactivation of tumor suppressor gene TP53, each subtype harbors its own specific genetic variations such as $c-M E T$ in ADC, fibroblast growth factor receptor 1 (FGFR1) and FGFR3 in SCC.
DNA methylation is a part of the epigenetic gene regulation complex and plays a critical role in carcinogenesis [5]. Recently, specific molecular alterations that drive tumor growth and provide targets for therapy have been defined in $\mathrm{ADC}$, but there is increasing interest in the molecular landscape of SCC highlighting new potential therapeutic targets [6]. Checkpoint with Forkhead-associated and Ring finger domains $(C H F R)$ is a $\mathrm{G} 2 / \mathrm{M}$ checkpoint gene that has been identified by Scolnik and Halazonetis [7]. This protein contains a forkhead and a RING finger domain, and functions as an ubiquitin ligase that ubiquitinates target proteins to direct them to the proteasome for degradation or to alter their activity $[8,9]$. The growing evidence supports its role as a tumor-suppressor protein and biomarker for chemotherapeutic response to microtubule-targeting drugs such as taxanes [9]. CHFR promoter hypermethylation has been observed in several tumors such as $30 \%$ in esophageal cancer [10], 20\% in NSCLC [11] and 40\% in colorectal 
cancer (CRC) [12]. However, the frequency of CHFR hypermethylation in NSCLC was inconsistent, and its contribution to the development and progression of NSCLC are unclear due to the small power of individual study. Therefore we pooled nine studies and performed a metaanalysis to evaluate the clinicopathologic significance of CHFR hypermethylation in NSCLC.

\section{RESULTS}

\section{Identification of relevant studies and quality assessment}

A total of nine studies were included in the metaanalysis (Figure 1) and 816 participants from five countries were involved. The study characteristics was summarized in Table 1. Based on the quality evaluation with the Newcastle-Ottawa Quality Assessment Scale (NOQAS), the overall quality of nine studies was scored from six to eight which indicated good quality (data not shown).

\section{The frequency of $\mathrm{CHFR}$ promoter methylation in $\mathrm{AC}$ and $\mathrm{SCC}$, and the association with the status of smoking}

Of the total 678 NSCLC patients from nine studies, aberrant $C H F R$ promoter methylation was identified in 106 patients, the frequency was $15.6 \%$. Three studies reported the comparison of $C H F R$ promoter methylation in

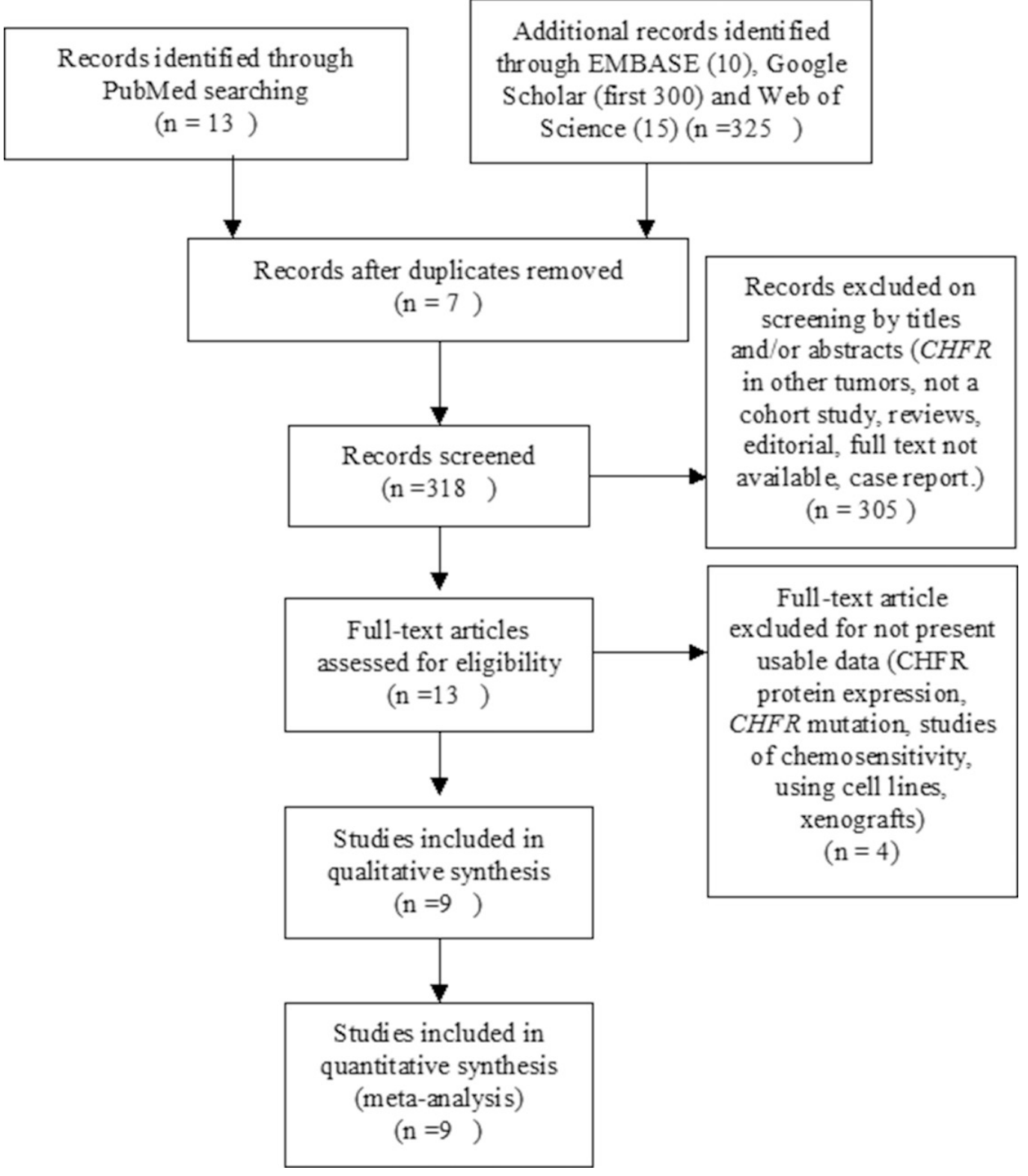

Figure 1: Schematic flow diagram for selection of included studies. 
Table 1: Main characteristics of included studies

\begin{tabular}{|c|c|c|c|c|c|c|c|c|c|c|c|c|c|}
\hline \multirow{2}{*}{ Author } & \multirow{2}{*}{ Year } & \multirow{2}{*}{ Country } & \multirow{2}{*}{$\begin{array}{c}\text { Sample size } \\
\text { (NSCLC) }\end{array}$} & \multicolumn{3}{|c|}{ Histology } & \multicolumn{2}{|c|}{ Stage (TNM) } & \multicolumn{2}{|c|}{ Grade } & \multicolumn{2}{|c|}{ Smoking status } & \multirow{2}{*}{ Method } \\
\hline & & & & NCT & ADC & SCC & I+II & III+IV & $\mathbf{L}$ & H & + & - & \\
\hline Guo [22] & 2015 & USA & $20 / 195$ & $1 / 100$ & $7 / 101$ & $13 / 94$ & $11 / 100$ & $2 / 25$ & - & - & - & - & MSP \\
\hline Pillai [42] & 2013 & Japan & $1 / 32$ & - & - & - & - & - & - & - & - & - & MSP \\
\hline Koga [21] & 2011 & Japan & $28 / 205$ & - & $16 / 165$ & $12 / 40$ & $26 / 183$ & $3 / 226$ & $4 / 71$ & $25 / 135$ & $23 / 126$ & $6 / 82$ & MSP \\
\hline Salazar [43] & 2011 & Spain & $32 / 91$ & - & - & - & - & - & - & - & - & - & MSP \\
\hline Takeshita [20] & 2010 & Japan & $11 / 68$ & - & $2 / 48$ & $9 / 20$ & $10 / 56$ & $1 / 12$ & - & - & $11 / 48$ & $0 / 21$ & MSP \\
\hline De Jong [44] & 2009 & Belgium & $2 / 10$ & $0 / 18$ & - & - & - & - & - & - & - & - & MSP \\
\hline Takeshita[45] & 2008 & Japan & $3 / 20$ & - & - & - & - & - & - & - & - & - & MSP \\
\hline Corn [39] & 2003 & USA & $2 / 20$ & $0 / 20$ & - & - & - & - & - & - & - & - & MSP \\
\hline Mizuno [11] & 2002 & Japan & $7 / 37$ & - & - & - & - & - & - & - & - & - & MSP \\
\hline
\end{tabular}

MSP: methylation-specific PCR, NCT: normal control tissue; AC: Adenocarcinoma; SCC: Squamous Cell Cancer; L: low grade; H: high grade;

NSCLC and normal lung tissue, the pooled rate of CHFR promoter methylation was significantly higher in NSCLC than normal lung tissue, OR was $9.92,95 \%$ CI 2.17-45.23, test for overall effect, $Z=2.96, p=0.003$ (Figure 2). Three studies investigated $C H F R$ promoter methylation in a total of $314 \mathrm{AC}$ and $154 \mathrm{SCC}$ respectively, CHFR promoter methylation in 34 out of 154 SCC (22.1\%) and 25 out of $314 \mathrm{AC}(8.0 \%)$ were identified. The frequency of CHFR promoter methylation was significantly higher in SCC than AC, OR was 4.46, 95\% CI 1.65-12.05, test for overall effect, $Z=2.95, p=0.003$ (Figure 3). Two studies investigated the relationship between $C H F R$ promoter methylation in NSCLC and the status of smoking, pooled data indicated that $C H F R$ promoter was more frequently methylated in smoking NSCLC patients than in non- smoking patients, OR was 3.67 with $95 \%$ CI $1.52-8.88$, test for overall effect, $\mathrm{Z}=2.89, p=0.004$ (Figure 4).

\section{The association between $C H F R$ promoter methylation and NSCLC stages as well as prognosis}

CHFR promoter methylation was not associated with NSCLC stages, the frequency of CHFR promoter methylation in stage III/IV NSCLC was not significantly increased compared to stage I/II NSCLC, OR was 0.26 , 95\% CI 0.06-1.13, test for overall effect, $Z=1.79, p=$ 0.007 (Figure 5). Two studies showed CHFR promoter methylation or low CHFR expression was correlated with poor prognosis, respectively. (Table 2).

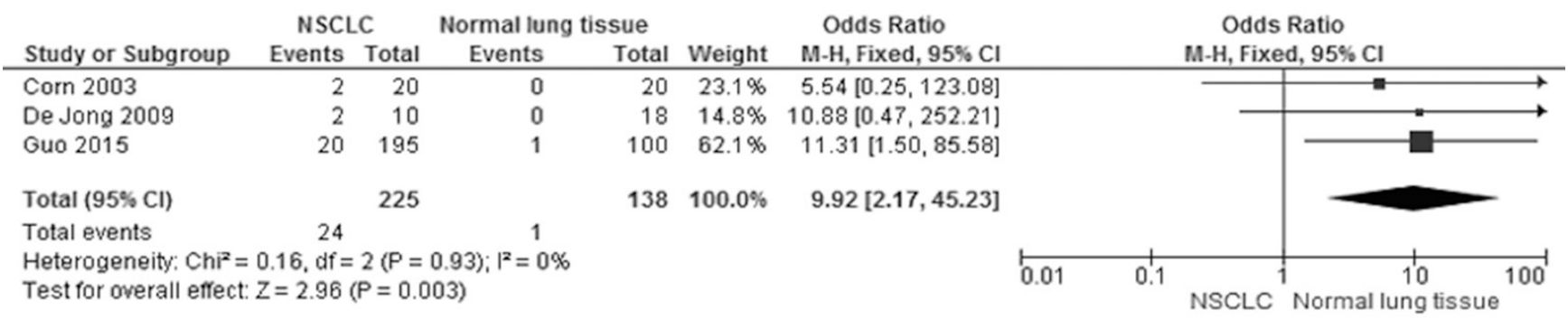

Figure 2: Forest plot for $\boldsymbol{C H F R}$ promoter methylation in NSCLC and normal lung tissue. The squares represent the weight of individual study in the meta-analysis, the line width indicates the corresponding $95 \% \mathrm{CI}$, The diamond represents the pooled OR, and the width of diamond indicates $95 \% \mathrm{CI}$.

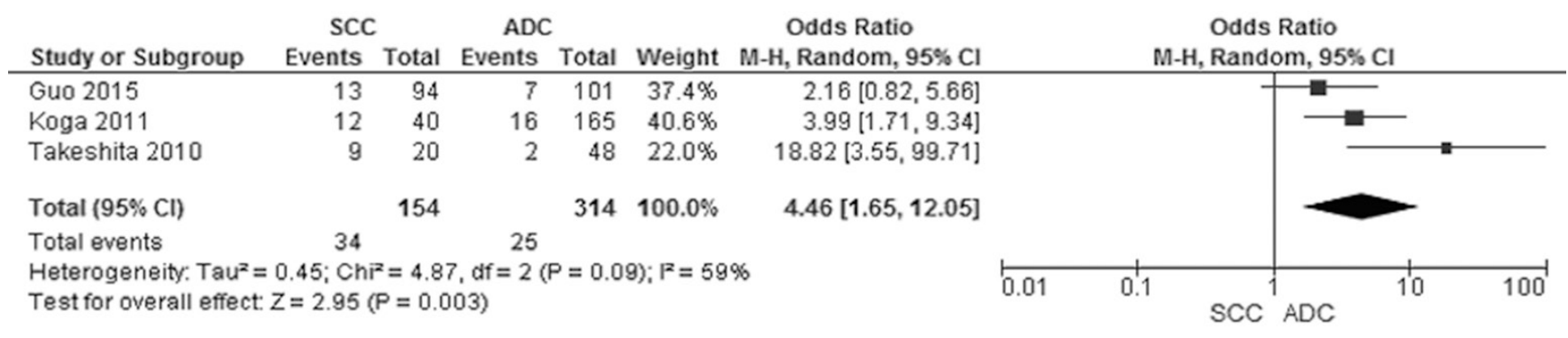

Figure 3: Forest plot for $\boldsymbol{C H F R}$ promoter methylation in SCC and ADC. The squares represent the weight of individual study in the meta-analysis, the line width indicates the corresponding $95 \% \mathrm{CI}$, The diamond represents the pooled OR, and the width of diamond indicates $95 \% \mathrm{CI}$. 


\section{Sensitivity analysis and publication bias}

A sensitivity analysis was performed by removing one study at a time, the ORs were not significantly changed, indicating the stability of present meta-analysis (Supplementary Figure 1, Supplementary Figure 2, Supplementary Figure 3, Supplementary Figure 4). The funnel plots were largely symmetric (Figure 6), suggesting there was no publication biases existed in the meta-analysis of relationship between CHFR promoter methylation and clinicopathological characteristics.

\section{DISCUSSION}

Scolnik and Halazonetis were the first to report the lack of $C H F R$ gene in colorectal cancer and neuroblastoma cell lines, after then loss of CHFR expression has been observed in a variety of malignancies such as colorectal cancer [12-14], gastric cancer [15-18], esophageal cancer $[10,19]$ and NSCLC [20-22]. Previous evidence indicated $C H F R$ was mostly inactivated by its promotor $\mathrm{CpG}$ island methylation [23]. CHFR promoter methylation has been observed in NSCLC, however, the frequency varied from $3.1 \%$ to $35.1 \%$ due to small size of samples. We pooled nine studies together and calculated the frequency of CHFR promoter methylation in 678 NSCLC patients, it was $15.6 \%$. Three studies evaluated the rate of CHFR promoter methylation in NSCLC and normal lung tissue, pooled OR suggested CHFR promoter methylation in NSCLC was ten times higher than in normal lung tissue. Previous evidence indicated that CHFR interacts with beta-tubulin and TCTP (Translationally Controlled Tumor-associated Protein) to stabilize microtubule [24]. Disruption of spindle cause CHFR deliberate from TCTP and spindle, this process results in the activation of signal pathway and delay cell cycle progression [25]. CHFR regulates the coordination of chromosome condensation and centrosome separation during prophase [7]. Thus, loss of CHFR causes errors in chromosome segregation that can lead to neoplasia [9]. Additional studies indicated that CHFR ubiquitinates and targets both polo-likekinase (PLK1) and Aurora A, leads to the inhibition of phosphorylation of cell division cycle 25 (Cdc25), which in turn control the $\mathrm{Cdc} 2$ kinase activity at $\mathrm{G} 2$ to $\mathrm{M}$ transition [26-30]. Ultimately, the cyclin B1-Cdk complex is not able to form and the cell cycle is arrested $[29,31]$. Therefore, the cells with CHFR gene inactivated by promoter methylation cannot be arrested in the $\mathrm{G} 2$ phase and proceed to mitosis, and proliferation and abnormal differentiation leads to the development of NSCLC and its progression.

Further subgroup analysis revealed that CHFR promoter was more frequently methylated in SCC than ADC, OR was 4.46 with $95 \%$ CI $1.65-12.05, p=0.003$ (Figure 3), suggesting that inactivation of CHFR gene was associated with the development of SCC. The molecular mechanism of pathogenesis is probably different between SCC and ADC. In addition, prior studies demonstrated that the loss of several suppressor genes such as Wnt inhibitory factor-1 (Wif1) [32], Phosphatase and tensin homolog deleted on chromosome 10 (PTEN) [33] and TP53 [34 36] occurred more frequently in SSC than in ADC. P53

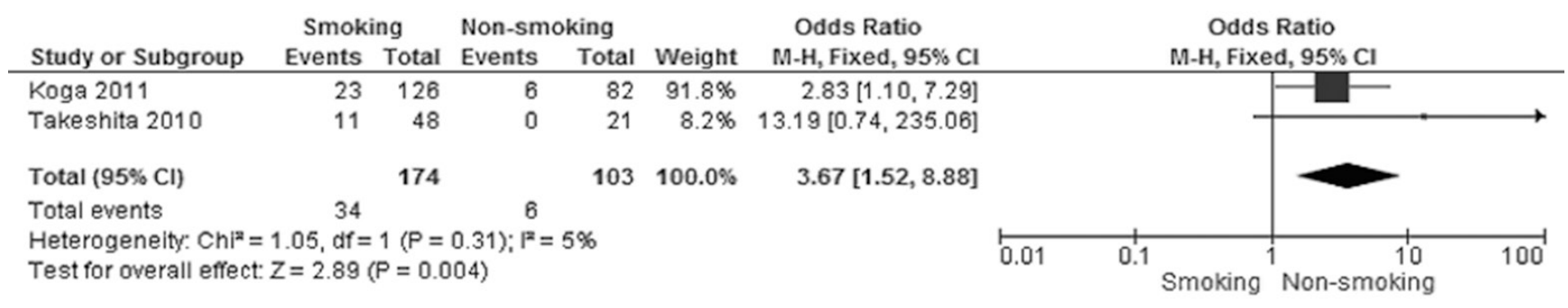

Figure 4: Forest plot for CHFR promoter methylation in NSCLC patients with smoking and non-smoking behavior. The squares represent the weight of individual study in the meta-analysis, the line width indicates the corresponding $95 \% \mathrm{CI}$, The diamond represents the pooled OR, and the width of diamond indicates $95 \% \mathrm{CI}$.

\begin{tabular}{|c|c|c|c|c|c|c|c|c|c|c|}
\hline \multirow[b]{2}{*}{ Study or Subgroup } & \multicolumn{2}{|c|}{ Stage IIIIV } & \multicolumn{2}{|c|}{ Stage $1 / 1 \mathrm{I}$} & \multirow[b]{2}{*}{ Weight } & \multirow{2}{*}{$\begin{array}{c}\text { Odds Ratio } \\
\mathrm{M}-\mathrm{H}, \text { Random, } 95 \% \mathrm{Cl}\end{array}$} & \multirow{2}{*}{\multicolumn{3}{|c|}{$\begin{array}{c}\text { Odds Ratio } \\
\mathrm{M}-\mathrm{H}, \text { Random, } 95 \% \mathrm{Cl}\end{array}$}} & \\
\hline & Events & Total & Events & Total & & & & & & \\
\hline Guo 2015 & 2 & 25 & 11 & 100 & $34.1 \%$ & $0.70[0.15,3.40]$ & & & & \\
\hline Koga 2011 & 3 & 226 & 26 & 183 & $40.4 \%$ & $0.08[0.02,0.27]$ & & & & \\
\hline Takeshita 2010 & 1 & 12 & 10 & 56 & $25.5 \%$ & $0.42[0.05,3.62]$ & & & & \\
\hline Total $(95 \% \mathrm{Cl})$ & & 263 & & 339 & $100.0 \%$ & $0.26[0.06,1.13]$ & & & & \\
\hline Total events & 6 & & 47 & & & & & & & \\
\hline $\begin{array}{l}\text { Heterogeneity: Tau² } \\
\text { Test for overall effect }\end{array}$ & $\begin{array}{l}1.03 ; \mathrm{Chi} \\
\mathrm{Z}=1.79\end{array}$ & $\begin{array}{l}2=5.10 \\
P=0.0\end{array}$ & $\begin{array}{l}\mathrm{df}=2( \\
7)\end{array}$ & $P=0.0$ & $8) ; F^{2}=61$ & & 0.01 & 0.1 Stage III/IV & Stage ${ }^{1 / 1}{ }^{10}$ & 100 \\
\hline
\end{tabular}

Figure 5: Forest plot for CHFR promoter methylation in NSCLC stage III/IV and stage I/II. The squares represent the weight of individual study in the meta-analysis, the line width indicates the corresponding $95 \%$ CI, The diamond represents the pooled OR, and the width of diamond indicates $95 \% \mathrm{CI}$. 
Table 2: The association between CHFR status and overall survival (HR) in NSCLC patients

\begin{tabular}{lccccc}
\hline Author & Sample Size & CHFR & HR & P value & Treatment \\
\hline Koga [21] & 208 & $\begin{array}{c}\text { Unmethylation vs. } \\
\text { Methylation } \\
\text { Nuclear stain High vs. } \\
\text { Low }\end{array}$ & $3.44(1.15-10.29)$ & 0.0274 & Surgery \\
Takeshita [45] & 157 & $\begin{array}{c}3.260(1.189-8.938) \\
\text { L }\end{array}$ & Surgery \\
\hline
\end{tabular}

mutations were the most common one in SCC, occurring at $50 \%$ of cases, however there was no relationship between CHFR expression and p53 mutation [37], indicating CHFR may contribute the carcinogenesis of SCC independently. Interestingly, present data showed that $C H F R$ promoter methylation was associated with smoking behavior which is a risk factor for the development of SSC [38]. Similarly, previous reports indicated that alterations of Wifl, PTEN and TP53 gene were associated with smoking behavior [32-35], suggesting that smoking behavior may lead to the squamous cell carcinogenesis by inducing the inactivation of those suppressor genes including CHFR gene.

Unlike ADC, there are no target therapies used in treatment of SCC patients, therefore, CHFR could be a
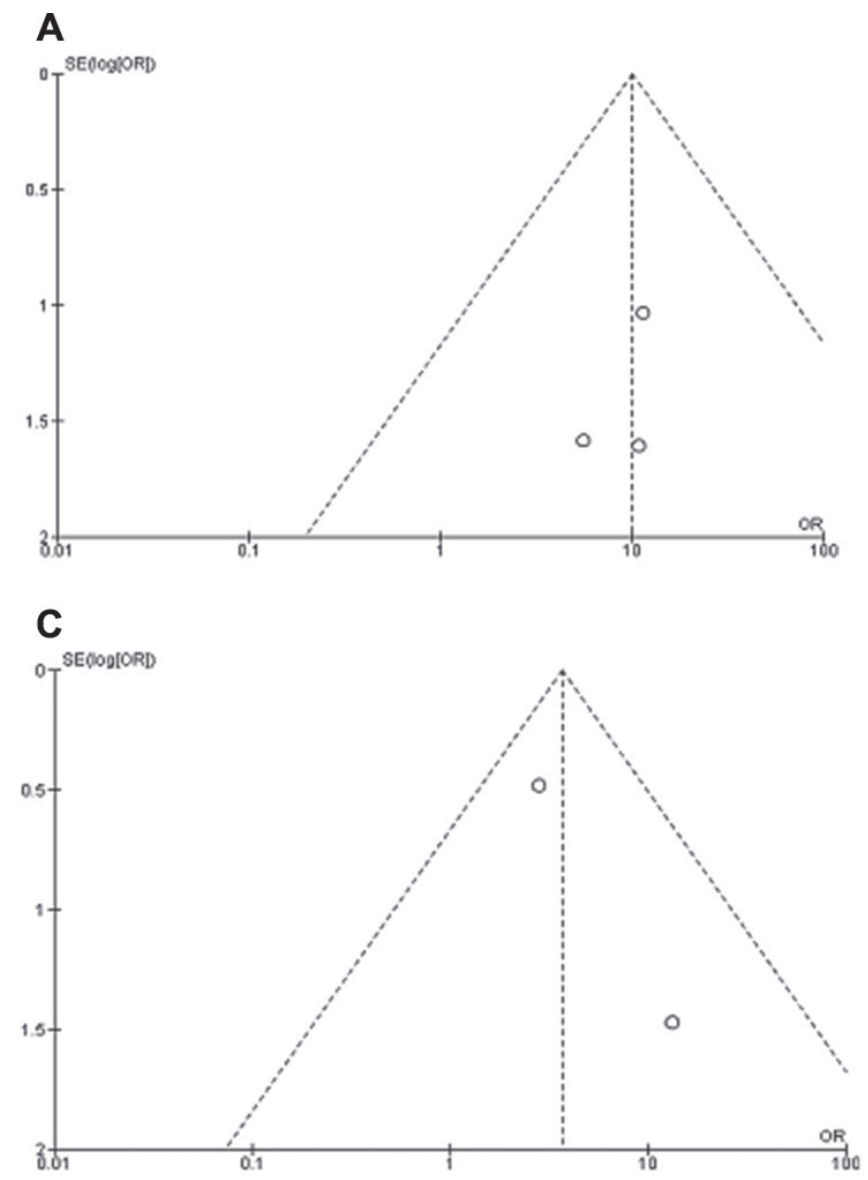

potential drug target for development of gene therapies in SCC via demethylation. Notably, in cancer cells with methylated $C H F R$, treatment with demethylation agent 5-aza-2-deoxycytidine led to re-expression of CHFR, and partially restored the prophase checkpoint [39]. Moreover demethylation agents such as azacitidine (AZA) has been demonstrated in reversing the effects of hypermethylation in solid tumors [40]. Thus, CHFR could be a very promising drug target for personalized treatment in patients with SCC.

The frequency of CHFR promoter methylation was higher in stage I/II of NSCLC than in stage III/IV, showing that $C H F R$ methylation occurred at early stage during the development of NSCLC. Additional analysis needs to

B

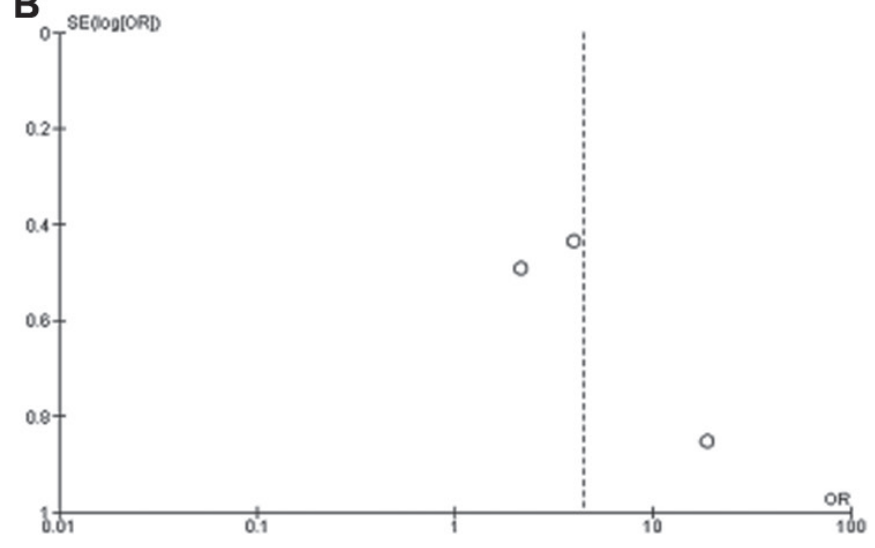

D

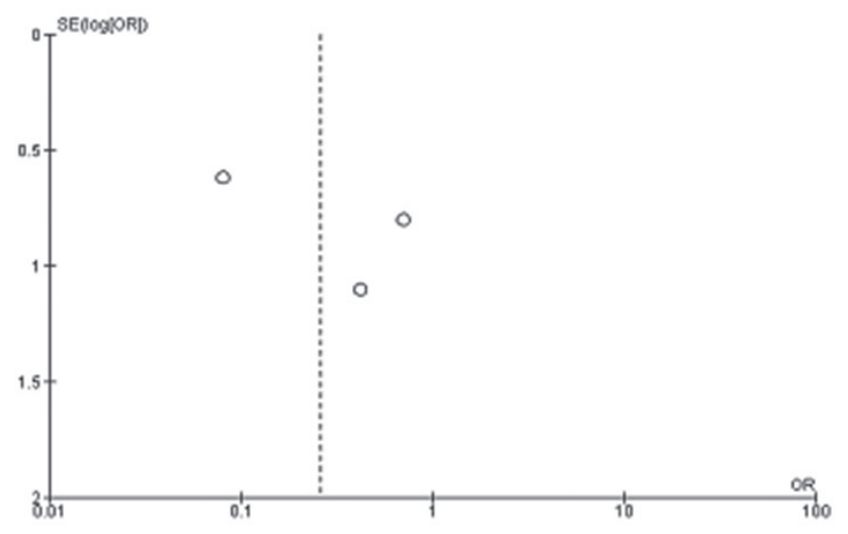

Figure 6: Funnel plot for publication bias. (A) $C H F R$ promoter methylation in NSCLC and normal lung tissue; (B) $C H F R$ promoter methylation in SCC and ADC; (C) CHFR promoter methylation in NSCLC patients with smoking and non-smoking behavior; (D) CHFR promoter methylation in NSCLC stage III/IV and stage I/II. S.E., standard error; Area of the circle represents the weight of individual study. 
be carried out when more relevant studies are available. CHFR promoter methylation was potentially associated with the overall survival based on the two included studies, although further studies will be needed to broadly establish this association in NSCLC.

The limitations of this meta-analysis are as follows, first, present findings were based on individual unadjusted ORs, and further confirmation needs to be finished by other potential risk factors. The second, publication bias may exist, as positive results were more likely published. The third, there are some clinical and statistical heterogeneity between the included studies. The fourth, most included studies are from Japan, therefore, the finding of the metaanalysis should be interpreted with caution.

In conclusion, $C H F R$ promoter methylation is correlated with the risk of SSC development. CHFR could be a potential biomarker and drug target to develop personalized treatment for the patients with SCC. CHFR promoter methylation is associated with smoking behavior.

\section{MATERIALS AND METHODS}

\section{Study identification}

Searches were performed from the earliest available data to July 2017 in PubMed, EMBASE, Web of Science and google scholar. The search terms were "non-small cell lung cancer", "NSCLC", "methylation", and "CHFR, or Checkpoint with Forkhead-associated and Ring finger domains". There were 13 articles identified from PubMed, 15 articles from Web Science, 10 articles from Embase. 1940 articles were identified from Google scholar, first 300 of them were reviewed since the rest of them are not related to the present study. The reference lists of Included studies were checked for any further relevant citations.

The inclusion criteria consisted of the following: 1). Articles evaluated methylation of CHFR in NSCLC; 2). Articles studied the relationship between $C H F R$ methylation and clinicopathological features in NSCLC. Exclusion criteria were studies using cell line and human xenografts, as well as using the same population and overlapping database. The flow chart of searches is shown in Figure 1.

\section{Data extraction}

Primary data were extracted by using a customized form which included first author, year of publication, geography location, methylation methods, histology categories of NSCLC, stages, grades and status of smoking. Two reviewers extracted the data independently, any disagreements were discussed until a consensus was reached.

\section{Quality assessment}

The methodological quality of included studies was evaluated using NOQAS. This scale was used to allocate a maximum of nine points, $0-4$ points for selection, $0-2$ points for comparability, 0-3 points for outcomes. The NOS scores ranged from 0 to 9 , and a score $\geq 7$ indicates a good quality. All studies were rated by two reviewers independently, any disagreements were discussed until a consensus was reached.

\section{Statistical analysis}

The pooled ORs with its $95 \%$ confidence intervals were calculated. The heterogeneity among studies was determined by using the Cochran's Q statistic and $I^{2}$ tests. When the $I^{2}$ value was below $50 \%$, fixed effect model was used, when the $I^{2}$ value was $50 \%$ or greater, a random effect model was used. Publication bias was assessed by using a method reported by Egger et al. [41]. The meta-analysis was performed using Review Manager 5.3 (Cochrane Collaboration, Software Update, Oxford, UK). $P$-value less than 0.05 was considered statistically significant.

\section{Author contributions}

CW, WM, RW and AD carried out the study, participated in collecting data and drafting the manuscript. $\mathrm{XZ}, \mathrm{NS}, \mathrm{LS}$, and LE performed the statistical analysis and participated in its design. YW, LG, XL, BW, and YZ contributed to the acquisition of data and interpretation of data. WM and AD have been involved in drafting and the critical revision of the manuscript. The corresponding author had full access to all data and the final responsibility for the decision to submit the article for publication. All authors read and approved the final manuscript.

\section{CONFLICTS OF INTEREST}

The authors declare that they have no competing interests, and have no any financial disclosures.

\section{REFERENCES}

1. Siegel RL, Miller KD, Jemal A. Cancer statistics, 2016. CA Cancer J Clin. 2016; 66:7-30.

2. Herbst RS, Heymach JV, Lippman SM. Lung cancer. N Engl J Med. 2008; 359:1367-1380.

3. Reck M, Popat S, Reinmuth N, De Ruysscher D, Kerr KM, Peters S, ESMO Guidelines Working Group. Metastatic nonsmall-cell lung cancer (NSCLC): ESMO Clinical Practice Guidelines for diagnosis, treatment and follow-up. Ann Oncol. 2014; 3:27-39.

4. Thakur MK, Wozniak AJ. Spotlight on necitumumab in the treatment of non-small-cell lung carcinoma. Lung Cancer (Auckl). 2017; 8:13-19.

5. Zhang Y, Wang DC, Shi L, Zhu B, Min Z, Jin J. Genome analyses identify the genetic modification of lung cancer 
subtypes. Semin Cancer Biol. 2017; 42:20-30.

6. Cooper WA, Lam DC, O'Toole SA, Minna JD. Molecular biology of lung cancer. J Thorac Dis. 2013; 5:S479-490.

7. Scolnick DM, Halazonetis TD. Chfr defines a mitotic stress checkpoint that delays entry into metaphase. Nature. 2000; 406:430-435.

8. Chaturvedi P, Sudakin V, Bobiak ML, Fisher PW, Mattern MR, Jablonski SA, Hurle MR, Zhu Y, Yen TJ, Zhou BB. Chfr regulates a mitotic stress pathway through its RINGfinger domain with ubiquitin ligase activity. Cancer Res. 2002; 62:1797-1801.

9. Privette LM, Petty EM. CHFR: A Novel Mitotic Checkpoint Protein and Regulator of Tumorigenesis. Transl Oncol. 2008; 1:57-64.

10. Shibata Y, Haruki N, Kuwabara Y, Ishiguro $H$, Shinoda N, Sato A, Kimura M, Koyama H, Toyama T, Nishiwaki T, Kudo J, Terashita Y, Konishi S, et al. Chfr expression is downregulated by $\mathrm{CpG}$ island hypermethylation in esophageal cancer. Carcinogenesis. 2002; 23:1695-1699.

11. Mizuno K, Osada H, Konishi H, Tatematsu Y, Yatabe Y, Mitsudomi T, Fujii Y, Takahashi T. Aberrant hypermethylation of the CHFR prophase checkpoint gene in human lung cancers. Oncogene. 2002; 21:2328-2333.

12. Toyota M, Sasaki Y, Satoh A, Ogi K, Kikuchi T, Suzuki H, Mita H, Tanaka N, Itoh F, Issa JP, Jair KW, Schuebel KE, Imai K, et al. Epigenetic inactivation of CHFR in human tumors. Proc Natl Acad Sci U S A. 2003; 100:7818-7823.

13. Derks S, Postma C, Carvalho B, van den Bosch SM, Moerkerk PT, Herman JG, Weijenberg MP, de Bruine AP, Meijer GA, van Engeland M. Integrated analysis of chromosomal, microsatellite and epigenetic instability in colorectal cancer identifies specific associations between promoter methylation of pivotal tumour suppressor and DNA repair genes and specific chromosomal alterations. Carcinogenesis. 2008; 29:434-439.

14. Kawasaki T, Ohnishi M, Nosho K, Suemoto Y, Kirkner GJ, Meyerhardt JA, Fuchs CS, Ogino S. CpG island methylator phenotype-low (CIMP-low) colorectal cancer shows not only few methylated CIMP-high-specific $\mathrm{CpG}$ islands, but also low-level methylation at individual loci. Mod Pathol. 2008; 21:245-255.

15. Kang HC, Kim IJ, Park JH, Shin Y, Park HW, Ku JL, Yang HK, Lee KU, Choe KJ, Park JG. Promoter hypermethylation and silencing of CHFR mitotic stress checkpoint gene in human gastric cancers. Oncol Rep. 2004; 12:129-133.

16. Koga Y, Kitajima Y, Miyoshi A, Sato K, Sato S, Miyazaki $\mathrm{K}$. The significance of aberrant CHFR methylation for clinical response to microtubule inhibitors in gastric cancer. J Gastroenterol. 2006; 41:133-139.

17. Honda T, Tamura G, Waki T, Kawata S, Nishizuka S, Motoyama T. Promoter hypermethylation of the Chfr gene in neoplastic and non-neoplastic gastric epithelia. Br J Cancer. 2004; 90:2013-2016.
18. Satoh A, Toyota M, Itoh F, Sasaki Y, Suzuki H, Ogi K, Kikuchi T, Mita H, Yamashita T, Kojima T, Kusano M, Fujita M, Hosokawa M, et al. Epigenetic inactivation of CHFR and sensitivity to microtubule inhibitors in gastric cancer. Cancer Res. 2003; 63:8606-8613.

19. Soutto M, Peng D, Razvi M, Ruemmele P, Hartmann A, Roessner A, Schneider-Stock R, El-Rifai W. Epigenetic and genetic silencing of CHFR in esophageal adenocarcinomas. Cancer. 2010; 116:4033-4042.

20. Takeshita M, Koga T, Takayama K, Yano T, Maehara Y, Nakanishi Y, Sueishi K. Alternative efficacy-predicting markers for paclitaxel instead of CHFR in non-small-cell lung cancer. Cancer Biol Ther. 2010; 10:933-941.

21. Koga T, Takeshita M, Yano T, Maehara Y, Sueishi K. CHFR hypermethylation and EGFR mutation are mutually exclusive and exhibit contrastive clinical backgrounds and outcomes in non-small cell lung cancer. Int J Cancer. 2011; 128:1009-1017.

22. Guo M, Alumkal J, Drachova T, Gao D, Marina SS, Jen J, Herman JG. CHFR methylation strongly correlates with methylation of DNA damage repair and apoptotic pathway genes in non-small cell lung cancer. Discov Med. 2015; 19:151-158.

23. Derks S, Cleven AH, Melotte V, Smits KM, Brandes JC, Azad N, van Criekinge W, de Bruine AP, Herman JG, van Engeland M. Emerging evidence for CHFR as a cancer biomarker: from tumor biology to precision medicine. Cancer Metastasis Rev. 2014; 33:161-171.

24. Yarm FR. Plk phosphorylation regulates the microtubule-stabilizing protein TCTP. Mol Cell Biol. 2002; 22:6209-6221.

25. van Vugt MA, Medema RH. Getting in and out of mitosis with Polo-like kinase-1. Oncogene. 2005; 24:2844-2859.

26. Li J, Williams BL, Haire LF, Goldberg M, Wilker E, Durocher D, Yaffe MB, Jackson SP, Smerdon SJ. Structural and functional versatility of the FHA domain in DNAdamage signaling by the tumor suppressor kinase Chk2. Mol Cell. 2002; 9:1045-1054.

27. Privette LM, Weier JF, Nguyen HN, Yu X, Petty EM. Loss of CHFR in human mammary epithelial cells causes genomic instability by disrupting the mitotic spindle assembly checkpoint. Neoplasia. 2008; 10:643-652.

28. Vader G, Lens SM. The Aurora kinase family in cell division and cancer. Biochim Biophys Acta. 2008; 1786:60-72.

29. Yu X, Minter-Dykhouse K, Malureanu L, Zhao WM, Zhang D, Merkle CJ, Ward IM, Saya H, Fang G, van Deursen J, Chen J. Chfr is required for tumor suppression and Aurora A regulation. Nat Genet. 2005; 37:401-406.

30. Gao YJ, Xin Y, Zhang JJ, Zhou J. Mechanism and pathobiologic implications of CHFR promoter methylation in gastric carcinoma. World J Gastroenterol. 2008; 14:5000-5007.

31. Burgess A, Labbe JC, Vigneron S, Bonneaud N, Strub JM, Van Dorsselaer A, Lorca T, Castro A. Chfr interacts and colocalizes with TCTP to the mitotic spindle. Oncogene. 2008; 27:5554-5566. 
32. Guo H, Zhou S, Tan L, Wu X, Wu Z, Ran R. Clinicopathological significance of WIF1 hypermethylation in NSCLC, a meta-analysis and literature review. Oncotarget. 2017; 8:2550-2557. https://doi.org/10.18632/ oncotarget. 13707.

33. Jin G, Kim MJ, Jeon HS, Choi JE, Kim DS, Lee EB, Cha SI, Yoon GS, Kim CH, Jung TH, Park JY. PTEN mutations and relationship to EGFR, ERBB2, KRAS, and TP53 mutations in non-small cell lung cancers. Lung Cancer. 2010; 69:279-283.

34. Tammemagi MC, McLaughlin JR, Bull SB. Metaanalyses of p53 tumor suppressor gene alterations and clinicopathological features in resected lung cancers. Cancer Epidemiol Biomarkers Prev. 1999; 8:625-634.

35. Cancer Genome Atlas Research Network. Comprehensive genomic characterization of squamous cell lung cancers. Nature. 2012; 489:519-525.

36. Ding L, Getz G, Wheeler DA, Mardis ER, McLellan MD, Cibulskis K, Sougnez C, Greulich H, Muzny DM, Morgan MB, Fulton L, Fulton RS, Zhang Q, et al. Somatic mutations affect key pathways in lung adenocarcinoma. Nature. 2008; 455:1069-1075.

37. Brodie SA, Li G, Brandes JC. Molecular characteristics of non-small cell lung cancer with reduced CHFR expression in The Cancer Genome Atlas (TCGA) project. Respir Med. 2015; 109:131-136.

38. Drilon A, Rekhtman N, Ladanyi M, Paik P. Squamous-cell carcinomas of the lung: emerging biology, controversies, and the promise of targeted therapy. Lancet Oncol. 2012; 13:e418-426.

39. Corn PG, Summers MK, Fogt F, Virmani AK, Gazdar AF, Halazonetis TD, El-Deiry WS. Frequent hypermethylation of the 5' $\mathrm{CpG}$ island of the mitotic stress checkpoint gene Chfr in colorectal and non-small cell lung cancer. Carcinogenesis. 2003; 24:47-51.

40. Valentini AM, Armentano R, Pirrelli M, Caruso ML. Chemotherapeutic agents for colorectal cancer with a defective mismatch repair system: the state of the art. Cancer Treat Rev. 2006; 32:607-618.

41. Egger M, Davey Smith G, Schneider M, Minder C. Bias in meta-analysis detected by a simple, graphical test. BMJ. 1997; 315:629-634.

42. Pillai RN, Brodie SA, Sica GL, Shaojin Y, Li G, Nickleach DC, Yuan L, Varma VA, Bonta D, Herman JG, Brock MV, Ribeiro MJ, Ramalingam SS, et al. CHFR protein expression predicts outcomes to taxane-based first line therapy in metastatic NSCLC. Clin Cancer Res. 2013; 19:1603-1611.

43. Salazar F, Molina MA, Sanchez-Ronco M, Moran T, Ramirez JL, Sanchez JM, Stahel R, Garrido P, Cobo M, Isla D, Bertran-Alamillo J, Massuti B, Cardenal F, et al. First-line therapy and methylation status of CHFR in serum influence outcome to chemotherapy versus EGFR tyrosine kinase inhibitors as second-line therapy in stage IV nonsmall-cell lung cancer patients. Lung Cancer. 2011; 72:8491.

44. De Jong WK, Verpooten GF, Kramer H, Louwagie J, Groen HJ. Promoter methylation primarily occurs in tumor cells of patients with non-small cell lung cancer. Anticancer Res. 2009; 29:363-369.

45. Takeshita M, Koga T, Takayama K, Kouso H, NishimuraIkeda Y, Yoshino I, Maehara Y, Nakanishi Y, Sueishi K. CHFR expression is preferentially impaired in smokingrelated squamous cell carcinoma of the lung, and the diminished expression significantly harms outcomes. Int $\mathbf{J}$ Cancer. 2008; 123:1623-1630. 